\title{
Study on Adiabatic Temperature Rise Reflecting Hydration Degree of Concrete
}

\author{
Yanhua Han, ${ }^{1,2}$ Shaojun Fu $\mathbb{D}^{1},{ }^{1}$ Shufa Wang, ${ }^{1}$ and Zuowei Xie ${ }^{1}$ \\ ${ }^{1}$ School of Civil Engineering, Wuhan University, 8 East Lake South Road, Wuhan 430072, China \\ ${ }^{2}$ School of Civil Engineering, Hubei Engineering University, 272 Traffic Avenue, Xiaogan 432000, China
}

Correspondence should be addressed to Shaojun Fu; sgjg@whu.edu.cn

Received 22 October 2017; Revised 4 January 2018; Accepted 5 February 2018; Published 5 April 2018

Academic Editor: Michael Aizenshtein

Copyright (c) 2018 Yanhua Han et al. This is an open access article distributed under the Creative Commons Attribution License, which permits unrestricted use, distribution, and reproduction in any medium, provided the original work is properly cited.

The thermal model and the relevant parameters of concrete are the most important issues to study the space-time characteristics of temperature field, which are also the theoretical foundation of temperature control and crack prevention for the mass concrete structures. In this research, the improved adiabatic temperature rise test is carried out, and the temperature variation of fly ash concrete is analyzed. Furthermore, a thermal model of concrete considering the hydration degree is established based on the existing achievements. Meanwhile, the thermal conductivity and specific heat of concrete are measured via three approaches: by treating the parameters as constant values, by computing the parameters as variables of the degree of hydration, and by backanalyzing the parameters through BP neural network. Finally, the thermal parameters determined by different methodologies are substituted into the thermal model, respectively, and the finite element analysis of the concrete specimen is performed. By comparing simulated temperatures with various measured results, it can be found that the numerical analysis results of parameters calculated by BP neural network are closest to the measured values in the whole curing ages. Therefore, BP neural network method is an effective way to calculate the thermal parameters, and BP inversion algorithm provides a new way for accurately study the temperature profile of mass concrete structures.

\section{Introduction}

Cracking is a common phenomenon in the concrete structures. Even some buildings which were carefully designed and constructed also appear with cracks. Among the numerous factors that cause the cracking of concrete, the temperature stress has been generally taken as the uppermost reason $[1,2]$. In the early ages, the temperatures of concrete change quickly with the rapid hydration of cement, and the temperature distributions in concrete structures are uneven because of the varied heat boundary conditions. The changes of both the temperature and the boundary conditions can lead to the obvious temperature gradients of the concrete structures, and the temperature gradients will lead to the temperature stress. The larger the temperature gradients are, the greater the temperature stress will become. Worst of all, the macrocracks will occur, and some of them will continue to expand and eventually form the penetrating cracks when the stress exceeds the tensile strength of concrete. And these penetrating cracks destroy the integrity of concrete structures and even become the potential hazards of the concrete constructions [3]. The changes of concrete temperature must be paid great attention in the design and construction process [4-11]. It is well known that the thermal model and the relevant parameters of concrete are the basic conditions for studying the space-time character of the temperature field and also are the prerequisite for accurate calculation of the temperature stress. The determinations of the thermal model and the relevant parameters are the key issues of studying the temperature. Therefore, it is necessary to carry out a thorough research.

In the simulation of concrete temperature field, the thermal model and its related parameters have big influences on the reliability and accuracy of the calculation results. The important factors affecting the thermal model include thermal conductivity, specific heat, adiabatic temperature 
rise, and surface heat dissipation coefficient, and so on. The above parameters may be acquired by experimental methods or empirical formulas in most cases $[4,5]$. However, the temperatures of concrete in the hardening process are affected by many complex factors, and the environmental condition of the laboratory is different from that of the construction site, both of which make it difficult to determine parameters precisely. Therefore, many researchers had adopted the advanced back analysis method to solve the problem [6-8]. But there were common shortcomings in the experimental method and in the numerical inversion method; thermal conductivity, specific heat, and other thermal parameters of concrete were regarded as constant values, and the changes of the concrete thermodynamic parameters in the hydration exothermic process were not taken into account. Hence, the temperatures simulated by the traditional thermal model with constant parameters are different from the experimental results because the actual engineering conditions cannot be well reflected.

In order to accurately predict the temperature distribution in the concrete, various factors that affect the temperature must be considered. It is known to all that the process of cement hydration is from the original flow state to plastic state and then to mature solidification. In addition, thermodynamic parameters also change with the transformation of the concrete status. De Schutter and Taerwe [9] studied the evolution of thermal parameters by means of experiments and literature summaries and indicated that thermal conductivity and specific heat of the early age concrete changed with the hydration degree. Kim et al. [10] researched the effects of water-cement ratio, curing age, temperature, and humidity on thermal conductivity through a series of experiments. Cui et al. [11] carried out some experiments to study the temperature change rules of the early-age concrete, introduced the thermal conductivity and specific heat considering the hydration degree, and simulated the temperature field by the finite element method. Those researchers started to know the relevant rules of changing the concrete thermal parameters and applied them into the thermal performance analysis of concrete structures. However, most existing researches focus on the early stage of concrete hydration, while the research on the real temperature evolution of concrete during the 28-day curing ages is not enough. Therefore, the thermal parameters need to be further refined.

Few researchers have addressed the thermal parameters considering the hydration degree during the whole $28 \mathrm{~d}$ curing ages. Over the years, the thermal parameters had been regarded as constant values when the temperature field of concrete was simulated, and the influence of the hydration degree on these parameters was ignored in most cases. And with the further study, the thermal parameters considering the hydration degree were only used to accurately simulate the early 7-day concrete hydration [11]. Therefore, it is urgent to research the thermal parameters considering the hydration degree during the entire curing ages, in order to provide suitable parameters for the thermal model and simulate the temperature field of concrete structure accurately.
Based on above facts, the adiabatic temperature rise tests of fly ash concrete with different water-cement ratios were firstly performed, the real-time temperatures at the testing points in the specimen were recorded during the whole curing ages, and then the temporal and spatial distribution of the concrete temperature field was analyzed carefully. A concrete thermal model considering the hydration degree was established according to the experiment and the available research achievements. Based on the experimental data, several important thermal parameters considering the hydration degree were retrieved by BP neural network to ensure that the thermal parameters are in line with the actual values of concrete hydration. Finally, the results from three different algorithms were compared and analyzed thoroughly, showing that the temperatures obtained from the approach proposed in this paper are closer to the experimental data than others.

\section{Adiabatic Temperature Rise Test}

In this study, the adiabatic temperature rise tests were carried out to accurately evaluate the effect of hydration heat on the temperature of fly ash concrete during the curing ages.

2.1. Raw Materials. An ordinary Portland cement with compressive strength of $42.5 \mathrm{~N} / \mathrm{mm}^{2}$ and the first-grade fly ash were selected as the cementing materials; the two materials complied with the Chinese National Standards GB175-2007 and GB/T 50146-2014, respectively, and the mass ratio of them was $1: 1$. The oxide contents and physical properties of the two materials are tabulated in Table 1 . Manufactured sand with a fineness modulus of 3.05 was selected as the fine aggregate, and the coarse aggregate was the crushed limestone of a continuous gradation $(5 \mathrm{~mm} \sim 80 \mathrm{~mm}$ with a maximum nominal size of $80 \mathrm{~mm}$ ).

$\mathrm{Ng}$ et al. [12] have presented that water-cement ratio $(w / c)$ has a great influence on the hydration degree, and the same hydration degree can be achieved when $\mathrm{w} / \mathrm{c}$ is close to 0.48 . It has been proved by Mill too. So two concrete specimens (named as C1 and C2) with w/c of 0.5 and 0.45 were prepared. The specific mix proportion of concrete in the test is indicated in Table 2.

2.2. Experimental Schemes. The adiabatic temperature rise chamber, provided by the Yangtze River Scientific Research Institute of China, was used to carry out the adiabatic tests of fly ash concrete. The specimen was a concrete cylinder with a diameter of $380 \mathrm{~mm}$ and a height of $360 \mathrm{~mm}$. In order to describe the temperatures of different positions in the concrete specimen, 13 testing points $\left(T_{0}, T_{1}, T_{2}, \ldots, T_{12}\right.$ in $\mathrm{C} 1$ and $T_{13}, T_{14}, T_{15}, \ldots, T_{25}$ in C2) were evenly arranged into 5 layers along the height direction of the concrete specimen (Figure 1). Micro K thermocouple detectors were adopted to provide quick and accurate temperature measurement, and a multichannel temperature measuring device was used to record the data according to the set intervals automatically. 
TABLE 1: Chemical composition and physical properties of the cementing materials.

\begin{tabular}{lccccccccc}
\hline Material & $\begin{array}{c}\mathrm{CaO} \\
(\%)\end{array}$ & $\begin{array}{c}\mathrm{SiO}_{2} \\
(\%)\end{array}$ & $\begin{array}{c}\mathrm{Al}_{2} \mathrm{O}_{3} \\
(\%)\end{array}$ & $\begin{array}{c}\mathrm{Fe}_{2} \mathrm{O}_{3} \\
(\%)\end{array}$ & $\begin{array}{c}\mathrm{MgO} \\
(\%)\end{array}$ & $\begin{array}{c}\mathrm{SO}_{3} \\
(\%)\end{array}$ & Loss of ignition $(\%)$ & $\begin{array}{c}\text { Density } \\
\left(\mathrm{kg} / \mathrm{m}^{3}\right)\end{array}$ & $\begin{array}{c}\text { The specific area } \\
\left(\mathrm{m}^{2} / \mathrm{kg}\right)\end{array}$ \\
\hline Cement & 57.72 & 35.48 & 0.87 & 1.20 & 3.49 & 2.42 & 1.26 & 3200 & 385 \\
Fly ash & 1.28 & 53.88 & 25.41 & 7.65 & 3.19 & 0.73 & 3.35 & 2600 & 414 \\
\hline
\end{tabular}

TABLE 2: Mixture proportion of concrete.

\begin{tabular}{lccccccc}
\hline Mix number & w/c & S/a & Water & Cement & Unit weight $\left(\mathrm{kg} / \mathrm{m}^{3}\right)$ & Fly ash & Sand \\
\hline C1 & & & 0.34 & 100 & 100 & 100 & 731 \\
C2 & 0.45 & 0.34 & 90 & 100 & 100 & 731 \\
\hline
\end{tabular}

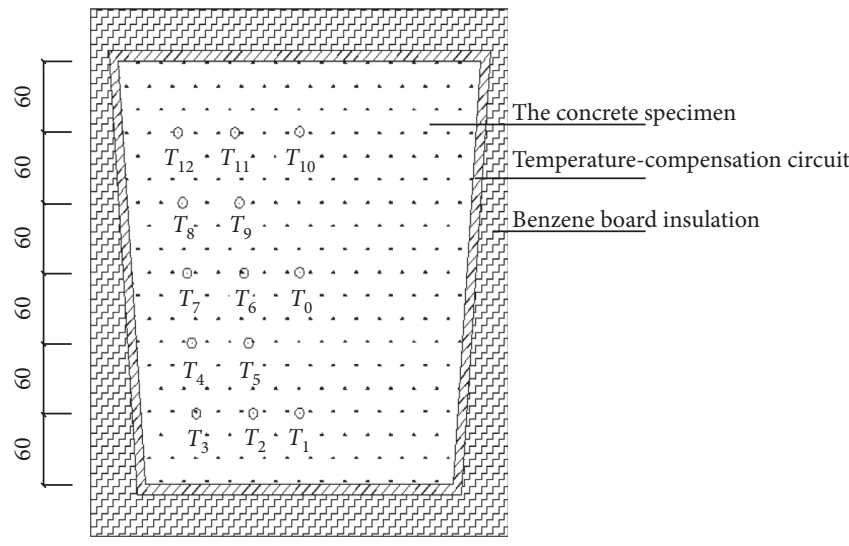

Figure 1: The location of sensors of adiabatic test (unit: $\mathrm{mm}$ ).

The temperature sensors fixed on a welded iron frame were wrapped with the epoxy resin asphalt to prevent damage during the concreting process and were put into the cylinder container as soon as the asphalt dried. The concrete was carefully poured through a funnel to ensure that the positions of sensors were not shifted, and at the same time, the concrete specimen was vibrated on the platform vibrator, and then the specimen was put into the outer cylinder after the surface was flattened. The whole experimentation was carried out under the room temperature of $25^{\circ} \mathrm{C}$, and the temperatures of the laboratory were adjusted timely according to the concrete specimen by air conditioner in order to ensure that the ambient temperatures are in accordance with the test temperatures during the adiabatic test. Figure 2 shows the concrete pouring, the insulation measures of the adiabatic chamber, and the temperature acquisition system in turn.

\subsection{Experimental Results}

2.3.1. The Temperature of Specimen with Different WaterCement Ratios. In each of the two specimens, three testing points were selected as representatives, and the historic curves of adiabatic temperature rise were plotted in order to give out the changes of temperature over time. Figure 3 presents the temperatures of the testing points in the two specimens which have taken account into the heat loss of the adiabatic chamber. It can be seen from Figure 3 that the temperatures of the both specimens are increasing with the increase of curing age, and the concrete is rapidly hydrated in the first few hours to reach a higher temperature, after which the rate of hydration becomes slow and the rate of temperature rise diminishes significantly. Meanwhile, we can also acquire from Figure 3 that the temperatures of $\mathrm{C} 2$ are lower than those of $\mathrm{C} 1$ in the whole process on account of the lower w/c. Moreover, the rising rates of $\mathrm{C} 1$ and $\mathrm{C} 2$ are slightly different; the temperature rising of $\mathrm{C} 1$ is faster than that of $\mathrm{C} 2$ at the beginning, and the increasing rates of the both are opposite at the later stage. The $\mathrm{w} / \mathrm{c}$ of $\mathrm{C} 1$ is relatively large which can provide adequate conditions for the hydration of cement leading to a faster hydration rate at the beginning while the w/c of $\mathrm{C} 2$ is smaller, and the cement cannot contact with water fully and the hydration rate is slow accordingly. With the curing ages increasing, the hydration of $\mathrm{C} 1$ is completed basically, while, by contrast, the internal temperature of $\mathrm{C} 2$ increases with the cement hydration, which is an important factor that promotes the hydration rate of cement, so the rate of $\mathrm{C} 2$ is slightly larger than that of $\mathrm{C} 1$ at a later period.

2.3.2. The Temperature at Different Positions of Specimen. Table 3 shows the temperatures at the testing points in the specimens $\mathrm{C} 1$ and $\mathrm{C} 2$ at different ages, and the spatial distribution of temperature is nonuniform obviously. The data of the testing points $T_{0}, T_{6}$, and $T_{7}$ and $T_{25}, T_{18}$, and $T_{19}$ indicate that the temperature near concrete core is higher while it slightly decreases along the radius at the same curing ages, and this is mainly because that the heat loss compensation of the equipment is not sufficient.

Figure 4 shows the temperatures along the height section of $1 \mathrm{~d}, 3 \mathrm{~d}, 7 \mathrm{~d}, 14 \mathrm{~d}$, and $28 \mathrm{~d}$ after pouring, taking $\mathrm{C} 1$ as an example. Both of them manifest that the temperatures of the testing points vary a lot in the first curing days. The temperature of testing points near concrete core is highest among the five points at the same moment because more heat is dissipated through the top and bottom of the adiabatic chamber. What is more, the temperatures of the bottom are lower than those of the top in the early hydration process, but it' is the opposite after 3 days. It is just due to the fact that the top of the concrete in the pouring process is exposed to the air and the ambient temperature is higher, 


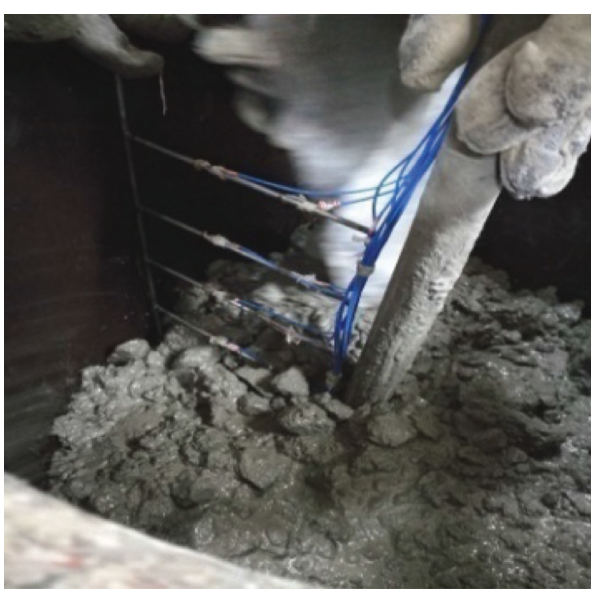

(a)

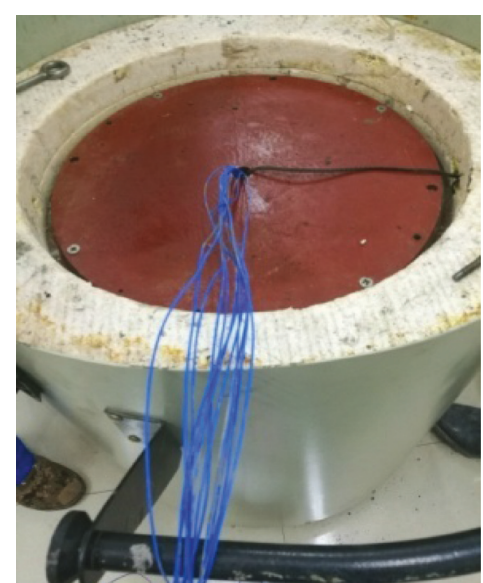

(b)

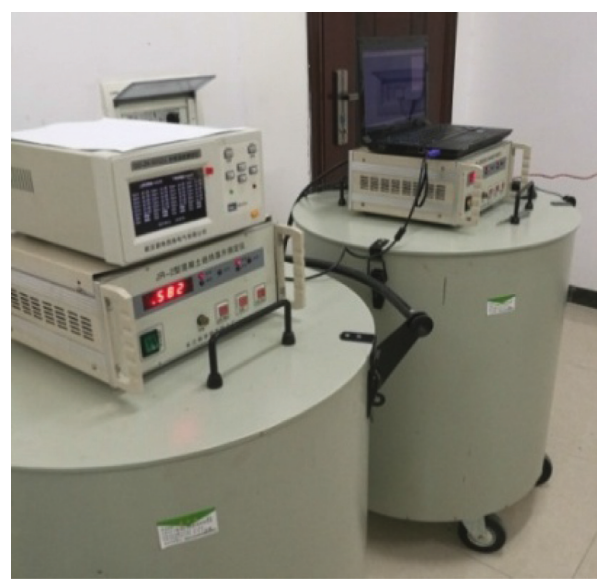

(c)

Figure 2: Experimental specimen and apparatus.

which improves the temperature of the top because of the heat transfer and leads to a faster hydration. As a result, the temperature of the top is higher at the early stage than later. After pouring, the external conditions of the top and the bottom are the same while the heat insulation effect of the bottom is better than that of the top during the hydration process. From Figure 4, it also can be shown that all the temperature changes have a similar trend, and the difference of the temperatures of the testing points becomes small from the third curing day.

\section{Thermal Governing Equations considering the Hydration Degree}

The appropriate thermal governing equations considering the hydration degree must be required in the numerical analysis. This section is intended to investigate a theoretical model which will be implemented in the numerical method.

\subsection{Thermal Governing Equations considering the Hydration} Degree. A cylinder specimen is frequently used in the adiabatic temperature rise test, so a calculation model of transient temperature field for concrete in cylindrical coordinates $(r, \varphi, z)$ needs to be established. According to the energy conservation law and the second law of thermodynamics, a domain undergoing thermal changes considering the hydration degree is subjected to the following field equation:

$$
\frac{\partial T}{\partial \tau}=\frac{\lambda(\alpha)}{c(\alpha) \rho}\left(\frac{\partial^{2} T}{\partial r^{2}}+\frac{1}{r} \cdot \frac{\partial T}{\partial r}+\frac{1}{r^{2}} \cdot \frac{\partial^{2} T}{\partial \varphi^{2}}+\frac{\partial^{2} T}{\partial z^{2}}\right)+\frac{Q(\alpha)}{c(\alpha) \rho},
$$

where $T$ is the temperature $\left({ }^{\circ} \mathrm{C}\right), \tau$ is the curing age $(\mathrm{d}), \rho$ is the density of concrete $\left(\mathrm{kg} / \mathrm{m}^{3}\right), \lambda(\alpha)$ is the thermal conductivity at the different hydration degree $\left(\mathrm{kJ} /\left(\mathrm{m} \cdot \mathrm{d} \cdot{ }^{\circ} \mathrm{C}\right)\right), c(\alpha)$ is the specific heat at the different hydration degree $\left(\mathrm{kJ} /\left(\mathrm{kg} \cdot{ }^{\circ} \mathrm{C}\right)\right)$, and $Q(\alpha)$ is the released heat associated with an internal source and is provided by the hydration reaction itself $\left(\mathrm{kJ} /\left(\mathrm{m}^{3} \cdot \mathrm{d}\right)\right)$.

The critical issues to simulate the temperature field of concrete is how to determine the hydration degree $\alpha$, thermal conductivity $\lambda(\alpha)$, specific heat $c(\alpha)$, and the released heat $Q(\alpha)$. Among the above parameters, the calculation of the hydration degree is the first step in determination of other three parameters.

3.2. The Hydration Degree. The solidifying process of concrete is accompanied by significant temperature changes, 


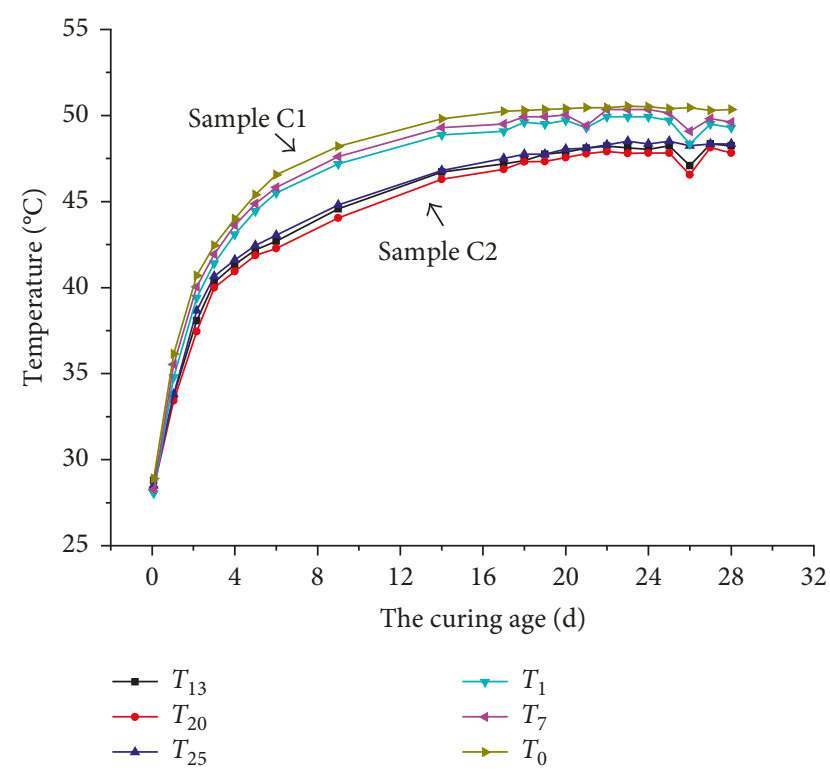

FIgURE 3: The temperature change of specimens at different sections $\left({ }^{\circ} \mathrm{C}\right)$.

TABle 3: The temperatures of specimens at different sections $\left({ }^{\circ} \mathrm{C}\right)$.

\begin{tabular}{lcccccc}
\hline \multirow{2}{*}{ The curing ages } & \multicolumn{6}{c}{ The sensor number } \\
& $T_{0}$ & $T_{6}$ & $T_{7}$ & $T_{25}$ & $T_{18}$ & $T_{19}$ \\
\hline $1 \mathrm{~d}$ & 36.2 & 35.6 & 35.5 & 35.5 & 33.5 & 33.6 \\
$3 \mathrm{~d}$ & 42.5 & 42.0 & 41.9 & 38.5 & 37.0 & 37.0 \\
$7 \mathrm{~d}$ & 46.6 & 45.9 & 45.8 & 40.4 & 38.7 & 38.7 \\
$14 \mathrm{~d}$ & 49.8 & 49.4 & 49.3 & 45.0 & 43.3 & 43.3 \\
$28 \mathrm{~d}$ & 50.4 & 49.9 & 49.8 & 49.8 & 47.8 & 47.8 \\
\hline
\end{tabular}

and the temperature rise is caused by the heat release of cementing materials reacting with water. Through the amount of the heat release, it is possible to calculate how much the hydration reaction has been completed at a certain curing age [13], which can be defined as the hydration degree. The ambient temperature has a significant effect on the hydration rate of concrete during the curing process, but it does not affect the maximum adiabatic temperature rise of concrete. Many thermal models adopt the concept of "equivalent age" to simplify the influence of temperature on the hydration rate. Equivalent age of the concrete is an artificial age which is concluded according to the actual temperature history, and it is determined through judging the result that the temperature has accelerated or delayed the aging process. For a certain type of concrete, there is a unique relationship between the adiabatic temperature rise and the equivalent age.

Saul [14] puts forward that regardless of the combination of time and temperature, the thermal performance of different positions in concrete specimen should be exactly identical as long as the maturity of concrete is the same. Based on the Arrhenius law which describes the effect of the temperature on the rate of chemical reaction, Professor Bazant [15] proposes the equation of the equivalent age, which can be used to calculate the hydration quantity in different hydration temperatures. The expression of the equivalent age is shown in the following:

$$
t_{\mathrm{e}}=\int_{0}^{t} \exp \left(\frac{E_{\mathrm{A}}}{R}\left(\frac{1}{T_{\mathrm{r}}}-\frac{1}{T}\right)\right) d t
$$

where $t_{\mathrm{e}}$ designates the equivalent age $(\mathrm{d}), E_{\mathrm{A}}$ is the reaction activation energy $(\mathrm{J} / \mathrm{mol}), R$ is the ideal gas constant $(\mathrm{J} /(\mathrm{K} \cdot \mathrm{mol})), T_{\mathrm{r}}$ is the reference temperature $(\mathrm{K})$, and $T$ is the actual temperature at any point of concrete $(\mathrm{K})$. Refer to the literature [11], $E_{\mathrm{A}} / R=2700 \mathrm{~K}, T_{\mathrm{r}}=20^{\circ} \mathrm{C}$, that is, $293 \mathrm{~K}$.

The thermal properties of concrete such as elastic modulus, hydration reaction, specific heat, thermal conductivity, and hydration heat are related to the hydration degree by which all of these indicators can be expressed. The models used frequently to calculate the hydration degree include complex exponential, hyperbolic, and exponential model. The hyperbolic model selected in this paper is expressed as follows:

$$
\alpha\left(t_{\mathrm{e}}\right)=\frac{m t_{\mathrm{e}}}{n+t_{\mathrm{e}}},
$$

where $\alpha\left(t_{\mathrm{e}}\right)$ is the hydration degree of concrete in the equivalent age (d) and both $m$ and $n$ are coefficients.

From the experimental results, it can be seen that the temperatures of concrete at different positions are similar, so the temperature of the concrete core is selected as the representative to study the relationship between the hydration degree and the equivalent age, shown in Figure 5. According to the measured temperatures expressed by black dots in Figure 5, the parameters $m$ and $n$ involved in (3) can be determined. For the specimen C1, $m=0.97$ and $n=2.78$; for the specimen $\mathrm{C} 2, m=0.98$ and $n=3.82$.

3.3. Heat Generation Rate. From (1), it can be seen that the hydration heat $Q(\alpha)$ is the sole heat-generated source leading to the temperature rise of concrete under adiabatic condition. Therefore, the heat generation rate of concrete considering the hydration degree under different temperatures can be formulated as

$$
\frac{d Q(\alpha)}{d t}=Q_{\infty} \times \frac{m \times n}{\left(n+t_{\mathrm{e}}\right)^{2}} \times \exp \left(\frac{E_{\mathrm{A}}}{R}\left(\frac{1}{T_{\mathrm{r}}}-\frac{1}{T}\right)\right),
$$

where $Q_{\infty}$ is the ultimate hydration heat quantity of concrete $\left(\mathrm{kJ} / \mathrm{m}^{3}\right)$.

\section{Determination of the Thermal Parameters}

In order to obtain the accurate temperatures of concrete during the curing ages, not only the governing equation of heat transfer needs to be established in the numerical simulation but also the thermal parameters based on the hydration degree of concrete need to be carefully taken into account. In this section, the relevant parameters of concrete were calculated by three methods listed below, respectively.

4.1. Thermal Parameters as Constant Values: Method 1. Thermal parameters needed in the thermal model of concrete were 


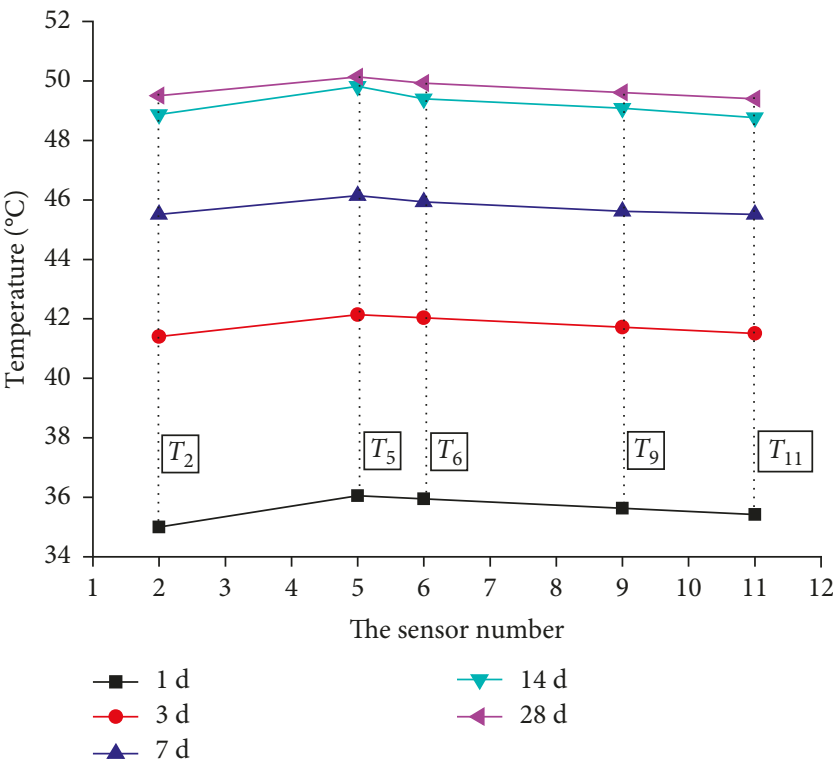

(a)

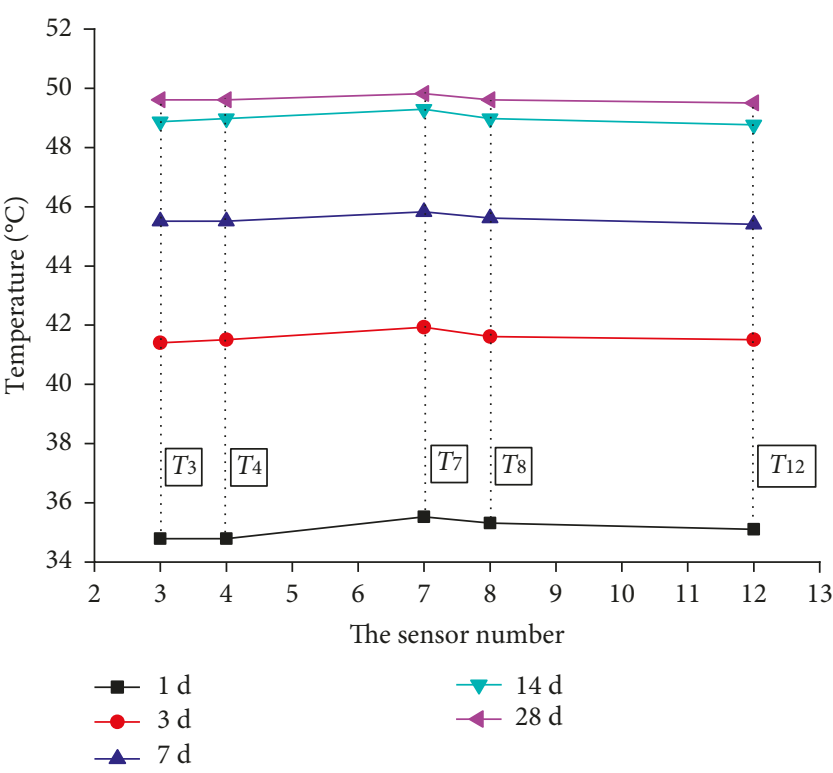

(b)

Figure 4: The temperature of the specimen $\mathrm{C} 1$ at different ages along the height section $\left({ }^{\circ} \mathrm{C}\right)$. (a) The temperature near concrete core. $(\mathrm{b})$ The temperature near concrete surface.

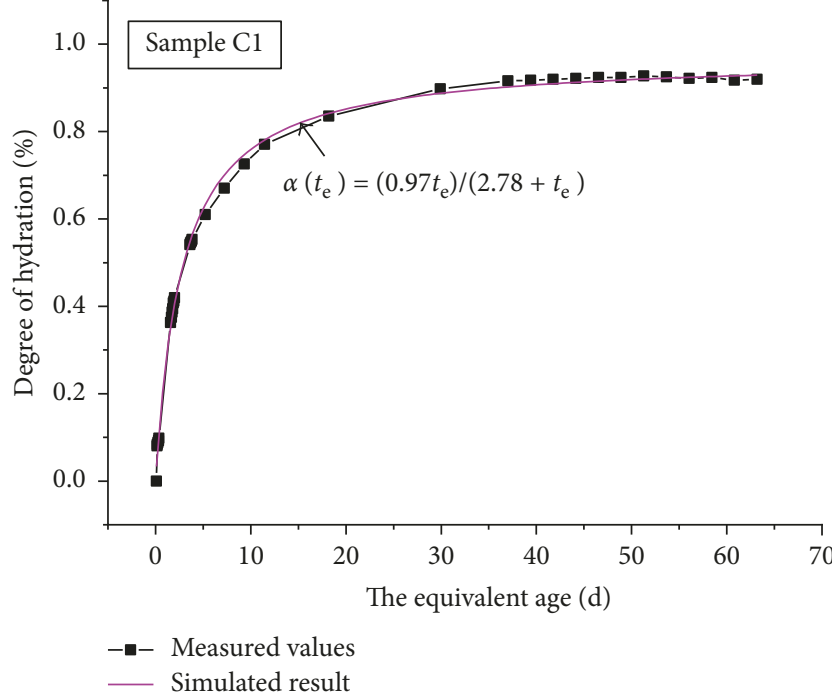

(a)

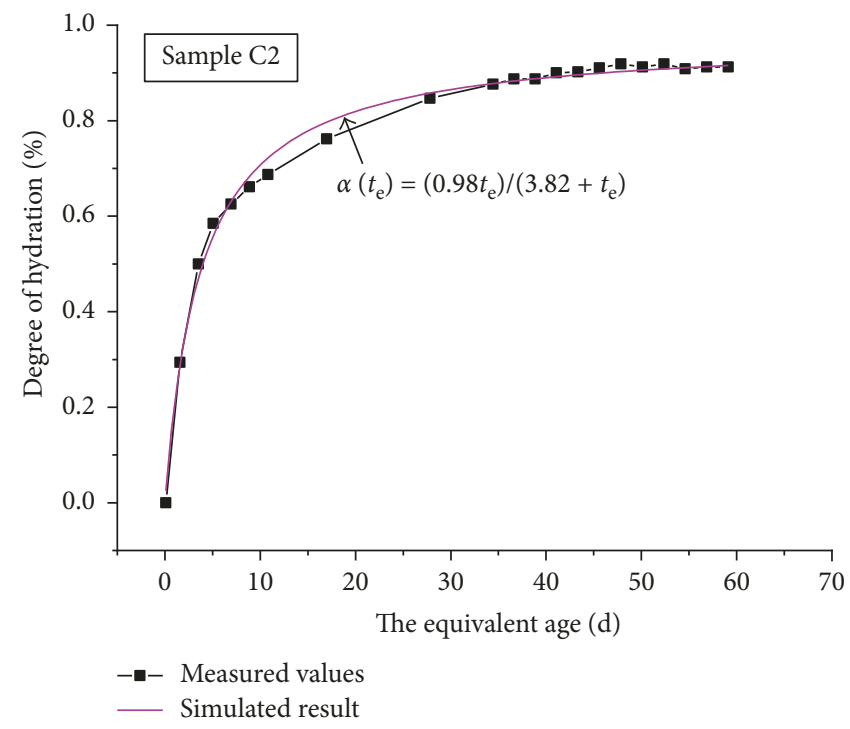

(b)

Figure 5: The relationship between the hydration degree and the equivalent age.

taken as constant values in some existing researches, and these values could be obtained by the test or by the empirical formula. The thermal conductivity and specific heat of fly ash concrete were determined by the method recommended in the literature [2] with the consideration of the ambient temperature. Moreover, the adiabatic temperature rise of fly ash concrete was fitted by the hyperbolic model, and the specific parameters are given in Table 4.

\subsection{Thermal Parameters considering the Hydration Degree:} Method 2. The thermal parameters in Table 4 characterize the properties of the solidified concrete, and the changes of thermal parameters during the concrete hardening cannot be reflected. In order to predict the concrete temperatures of the early curing ages more accurately, the variation of thermal properties during the hardening process should be taken into account.

4.2.1. Thermal Conductivity Coefficient. The thermal conductivity coefficient is an indicator which describes the heat capacity of concrete in the temperature field calculation, and it is affected by water-cement ratio, cement content, density, 
TABLE 4: The thermal parameters involved in Method 1.

\begin{tabular}{lccccc}
\hline $\begin{array}{l}\text { Mix } \\
\text { number }\end{array}$ & $\begin{array}{c}\text { Density } \\
\left(\mathrm{kg} / \mathrm{m}^{3}\right)\end{array}$ & $\begin{array}{c}\text { Thermal conductivity } \\
\left(\mathrm{kJ} / \mathrm{m} \cdot \mathrm{d} \cdot{ }^{\circ} \mathrm{C}\right)\end{array}$ & $\begin{array}{c}\text { Specific heat } \\
\left(\mathrm{kJ} / \mathrm{kg} \cdot{ }^{\circ} \mathrm{C}\right)\end{array}$ & $\begin{array}{c}\text { Ultimate adiabatic temperature } \\
\text { rise }\left({ }^{\circ} \mathrm{C}\right)\end{array}$ & $\begin{array}{c}\text { The corresponding } \\
\text { value }\end{array}$ \\
\hline $\mathrm{C} 1$ & 2450 & 285.344 & 0.921 & 25.5 & 1.83 \\
$\mathrm{C} 2$ & 2440 & 282.713 & 0.907 & 23.5 & 2.38 \\
\hline
\end{tabular}

TABLE 5: The thermal parameters involved in Method 2.

\begin{tabular}{lccccccrr}
\hline $\begin{array}{l}\text { Mix } \\
\text { number }\end{array}$ & $\begin{array}{c}\text { Density } \\
\left(\mathrm{kg} / \mathrm{m}^{3}\right)\end{array}$ & $\begin{array}{c}\text { Thermal conductivity } \\
\left(\mathrm{kJ} / \mathrm{m} \cdot \mathrm{d} \cdot{ }^{\circ} \mathrm{C}\right)\end{array}$ & $\begin{array}{c}c_{\mathrm{c}} \\
\left(\mathrm{kJ} / \mathrm{kg} \cdot{ }^{\circ} \mathrm{C}\right)\end{array}$ & $\begin{array}{c}c_{\mathrm{f}} \\
\left(\mathrm{kJJ} / \mathrm{kg} \cdot{ }^{\circ} \mathrm{C}\right)\end{array}$ & $\begin{array}{c}c_{\mathrm{s}} \\
\left(\mathrm{kJ} / \mathrm{kg} \cdot{ }^{\circ} \mathrm{C}\right)\end{array}$ & $\begin{array}{c}c_{\mathrm{a}} \\
\left(\mathrm{kJ} / \mathrm{kg} \cdot{ }^{\circ} \mathrm{C}\right)\end{array}$ & $\begin{array}{c}c_{\mathrm{w}} \\
\left(\mathrm{kJ} / \mathrm{kg} \cdot{ }^{\circ} \mathrm{C}\right)\end{array}$ & $\begin{array}{c}\text { The total heat } \\
\left(\mathrm{kJ} / \mathrm{m}^{3} \cdot \mathrm{d}\right)\end{array}$ \\
\hline $\mathrm{C} 1$ & 2450 & 289.956 & 0.485 & 0.92 & 0.716 & 0.752 & 4.187 & 57539.475 \\
$\mathrm{C} 2$ & 2440 & 286.291 & 0.485 & 0.92 & 0.716 & 0.752 & 4.187 & 52007.380 \\
\hline
\end{tabular}

temperature and humidity, and so on $[9,10,16,17]$. The formula of thermal conductivity coefficient proposed by Schindler is widely used, in which the effect of the hydration degree on thermal conductivity coefficient is taken into account [18], as shown in the following equation:

$$
\lambda(\alpha)=\lambda_{u}(1.33-0.33 \alpha)
$$

where $\lambda_{u}$ denotes the thermal conductivity coefficient of hardened concrete $\left(\mathrm{kJ} /\left(\mathrm{m} \cdot \mathrm{d} \cdot{ }^{\circ} \mathrm{C}\right)\right)$.

The parameter is further found to be linear with the temperature [2, 10]. Kim et al. [10] put forward a formula for correcting the thermal conductivity coefficient at different pouring temperatures with water-cement ratio above 0.4 :

$$
\lambda_{\mathrm{T}}=1.05-0.0025 T_{1} \text {, }
$$

where $\lambda_{\mathrm{T}}$ denotes the correction of the thermal conductivity coefficient at different pouring temperatures $\left(\mathrm{kJ} /\left(\mathrm{m} \cdot \mathrm{d} \cdot{ }^{\circ} \mathrm{C}\right)\right.$ ) and $T_{1}$ denotes the pouring temperatures $\left({ }^{\circ} \mathrm{C}\right)$.

According to the abovementioned equation, an integrated relationship about the thermal conductivity coefficient of concrete, pouring temperatures, and the hydration degree can be obtained:

$$
\lambda\left(\alpha, T_{1}\right)=\lambda_{u}(1.33-0.33 \alpha)\left(1.05-0.0025 T_{1}\right),
$$

where $\lambda\left(\alpha, T_{1}\right)$ is the thermal conductivity coefficient at different pouring temperatures and the hydration degree $\left(\mathrm{kJ} /\left(\mathrm{m} \cdot \mathrm{d} \cdot{ }^{\circ} \mathrm{C}\right)\right)$.

4.2.2. Specific Heat. It has been pointed out that the temperatures and water content have an important effect on specific heat $[9,19]$, and Van Breugel [20] further proposes a calculation model of specific heat considering temperature, mixing ratio, and the hydration degree. From the formula, it can be seen that the specific heat decreases linearly with the hydration degree:

$$
\begin{aligned}
c(\alpha) & =\frac{\omega_{\mathrm{c}} \alpha c_{\mathrm{cef}}+\omega_{\mathrm{c}}(1-\alpha) c_{\mathrm{c}}+\omega_{\mathrm{f}} c_{\mathrm{f}}+\omega_{\mathrm{s}} c_{\mathrm{s}}+\omega_{\mathrm{a}} c_{\mathrm{a}}+\omega_{\mathrm{w}} c_{\mathrm{w}}}{\rho}, \\
c_{\text {cef }} & =0.0084 T_{j}+0.339
\end{aligned}
$$

where $\omega_{\mathrm{c}}, \omega_{\mathrm{f}}, \omega_{\mathrm{a}}$, and $\omega_{\mathrm{w}}$ are the mass of cement, fly ash, aggregate, and water in per cubic meter of concrete, respectively $\left(\mathrm{kg} / \mathrm{m}^{3}\right) ; c_{c}, c_{\mathrm{f}}, c_{\mathrm{a}}$, and $c_{\mathrm{w}}$ are the specific heat of cement, fly ash, aggregate, and water, respectively $\left(\mathrm{kJ} /\left(\mathrm{kg} \cdot{ }^{\circ} \mathrm{C}\right)\right) ; c_{\text {cef }}$ is the artificial specific heat of cement $\left(\mathrm{kJ} /\left(\mathrm{kg} .{ }^{\circ} \mathrm{C}\right)\right)$; and $T_{j}$ is the actual temperature of cement at time $t_{j}\left({ }^{\circ} \mathrm{C}\right)$.

The equations of thermal conductivity coefficient and specific heat mentioned above are suitable to the early age concrete. In method 2, thermal parameters were calculated by (7) and (8) in the early curing ages; after 7 days, the corresponding parameters of concrete were taken as constant values. The parameters involved are listed in Table 5.

4.3. Thermal Parameters Inverted by BP: Method 3. The thermal parameters of concrete are affected by many factors such as ambient temperature, water-cement ratio, cement content, and aggregate content, and the influence of these factors may be dependent on each other. As a result, the thermal parameters are difficult to be accurately determined by the experiment. Furthermore, the incorporation of the fly ash can reduce the adiabatic temperature rise of concrete, which is due to the pozzolanic reaction of the fly ash, so the influence of the fly ash should be considered when the temperature of the fly ash concrete is calculated. However, the effect of the fly ash dosage on the calculation results cannot be quantitatively given. Nevertheless, BP neural network provides an effective approach for such complex situations. In this section, the thermal conductivity coefficient, specific heat, and the released heat considering the hydration degree will be predicted by BP neural network.

4.3.1. Target Function for BP Neural Network. The BP inversion method is to establish the relationship between the thermal parameters and the measured temperatures. The measured temperatures are the actual values obtained in the adiabatic test, which are the results of combined action of various factors including the pozzolanic reaction of the pulverised fuel ash. It can be expressed as

$$
\{T\}=\{g(x)\},
$$

where $T$ denotes the temperature $\left({ }^{\circ} \mathrm{C}\right)$ and $g(x)$ is the function of the various factors.

And the difference between the measured temperatures and the theoretical ones can be calculated by the following equation: 
TABLe 6: Sample data of back analysis with BP network.

\begin{tabular}{|c|c|c|c|c|c|}
\hline Sample numbers & $\alpha, \mathrm{C} 1(\mathrm{C} 2)$ & $\lambda(\alpha)\left(\mathrm{kJ} /\left(\mathrm{m} \cdot \mathrm{d} \cdot{ }^{\circ} \mathrm{C}\right)\right), \mathrm{C} 1(\mathrm{C} 2)$ & $c(\alpha)\left(\mathrm{kJ} /\left(\mathrm{kg} \cdot{ }^{\circ} \mathrm{C}\right)\right), \mathrm{C} 1(\mathrm{C} 2)$ & $\mathrm{Q}(\alpha)\left(\mathrm{kJ} /\left(\mathrm{m}^{3} \cdot \mathrm{d}\right)\right), \mathrm{C} 1(\mathrm{C} 2)$ & $T\left({ }^{\circ} \mathrm{C}\right), \mathrm{C} 1(\mathrm{C} 2)$ \\
\hline 1 & $0(0)$ & $377.59(373.27)$ & $0.876(0.864)$ & $0(0)$ & $26.7(27.1)$ \\
\hline 2 & $0.041(0.273)$ & $373.01(346.25)$ & $0.876(0.866)$ & $2246.67(13576.07)$ & $27.75(33.53)$ \\
\hline 3 & $0.058(0.454)$ & $371.57(328.34)$ & $0.876(0.867)$ & 3149.57 (22562.93) & $28.17(37.76)$ \\
\hline 4 & $0.053(0.553)$ & $370.17(319.94)$ & $0.876(0.869)$ & $2924.09(27552.24)$ & $28.06(40.10)$ \\
\hline 5 & $0.058(0.597)$ & $368.82(313.09)$ & $0.877(0.869)$ & $3150.02(29785.34)$ & $28.17(41.14)$ \\
\hline$\vdots$ & & & & & \\
\hline 146 & $0.899(0.907)$ & $290.51(287.93)$ & $0.887(0.874)$ & $49788.84(45449.35)$ & $47.4(47.82)$ \\
\hline 147 & $0.890(0.889)$ & $290.36(287.74)$ & $0.887(0.874)$ & $49329.58(44547.41)$ & $47.2(47.40)$ \\
\hline
\end{tabular}

Table 7: The thermal parameters calculated by Method 3.

\begin{tabular}{|c|c|c|c|c|c|}
\hline \multirow{2}{*}{ Sample numbers } & \multirow{2}{*}{$\begin{array}{c}\text { Input layer } \\
T_{0}\left({ }^{\circ} \mathrm{C}\right), \mathrm{C} 1(\mathrm{C} 2)\end{array}$} & \multicolumn{4}{|c|}{ Output layer } \\
\hline & & $\alpha, \mathrm{C} 1(\mathrm{C} 2)$ & $\lambda(\alpha)\left(\mathrm{kJ} /\left(\mathrm{m} \cdot \mathrm{d} \cdot{ }^{\circ} \mathrm{C}\right)\right), \mathrm{C} 1(\mathrm{C} 2)$ & $c(\alpha)\left(\mathrm{kJ} /\left(\mathrm{kg} \cdot{ }^{\circ} \mathrm{C}\right)\right), \mathrm{C} 1(\mathrm{C} 2)$ & $\mathrm{Q}(\alpha))\left(\mathrm{kJ} /\left(\mathrm{m}^{3} \cdot \mathrm{d}\right)\right), \mathrm{C} 1(\mathrm{C} 2)$ \\
\hline 1 & $26.9(26.9)$ & $0(0)$ & $383.362(373.324)$ & $0.875(0.864)$ & $0(0)$ \\
\hline 2 & $28.95(33.8)$ & $0.05(0.273)$ & $371.086(346.236)$ & $0.876(0.866)$ & $2862.496(24721.45)$ \\
\hline 3 & $29.05(38.65)$ & $0.05(0.499)$ & $371.136(325.802)$ & $0.876(0.868)$ & $2836.492(34463.63)$ \\
\hline$\vdots$ & $\vdots$ & $\vdots$ & $\vdots$ & - & \\
\hline 62 & $49.5(48.03)$ & $0.907(0.893)$ & $291.49(288.345)$ & $0.887(0.874)$ & $50232.90(44727.24)$ \\
\hline 63 & $49.29(47.72)$ & $0.908(0.893)$ & $291.44(288.345)$ & $0.887(0.874)$ & $50306.14(44727.24)$ \\
\hline
\end{tabular}

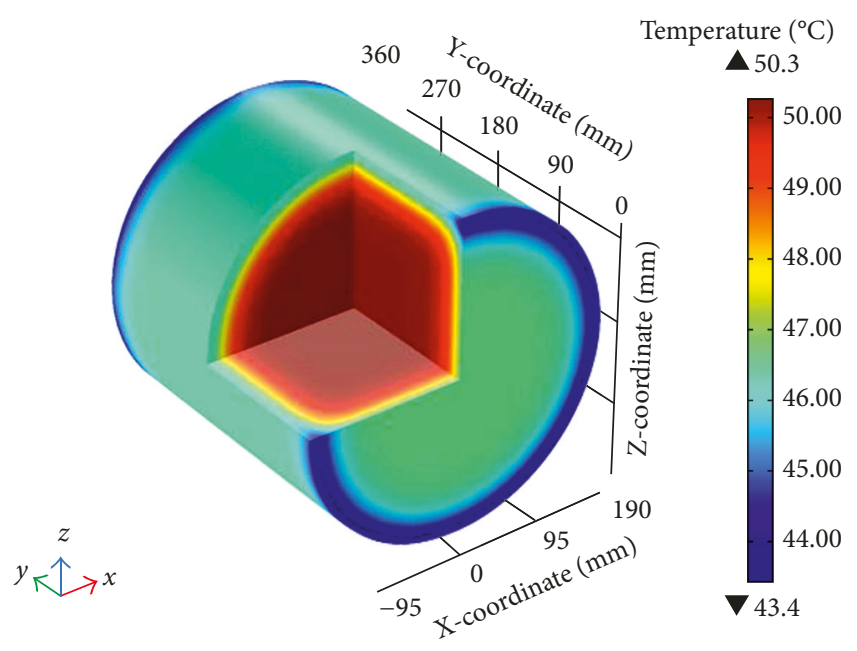

Figure 6: Temperature distribution of concrete specimen at the 28th day.

$$
\phi(x)=\sum_{i=1}^{n}\left(u_{i}-g_{i}(x)\right)^{2},
$$

where $x$ denote the factors that affect the temperature, such as $c(\alpha), \lambda(\alpha)$, and $Q(\alpha) ; \alpha$ and $u_{i}$ are the measured temperatures; $g_{i}(x)$ is the theoretical temperature; and $\phi(x)$ is the difference.

If the minimum value of (10) can be acquired through adjusting the range of affecting factors, then the theoretical values will match well with the measured ones. Therefore, the parameter inversion becomes an optimization problem in essence $[21,22]$.

4.3.2. Back Analysis Scheme. According to the mixing ratio of concrete and practical experience in engineering, the ranges of thermal parameters were determined. Considering the temperature changes of the different positions in the adiabatic temperature rise test, the temperatures of seven testing points from the top, bottom, and center of the specimens were selected as the representatives; the specific points were $T_{0}, T_{3}, T_{6}, T_{7}, T_{12}, T_{1}$, and $T_{10}$ of the specimen C1 and $T_{13}, T_{15}, T_{18}, T_{19}, T_{22}, T_{24}$, and $T_{25}$ of the specimen C2. The corresponding points of the above sensors in the temperature field calculation were chosen, and the temperatures at 21 different curing ages were selected at the same time; then 147 sets of training samples which were composed of thermal parameters and temperatures within the parameter range were generated for training networks (shown in Table 6).

The samples were first normalized when BP neural network was trained, and the temperatures and four thermal parameters were taken as the input values and the outputs, respectively, after which the network mapping relationship of the temperatures to thermal parameters could be achieved. In addition, (11) was used to estimate the hidden layer nodes, and the repeated trail calculations proved that the training error was minimal when the number of nodes was 10 .

$$
n_{\mathrm{h}}=\sqrt{n_{\mathrm{i}}+n_{\mathrm{o}}}+m
$$

where $n_{\mathrm{h}}$ denotes the hidden layer nodes, $n_{\mathrm{i}}$ denotes the input layer nodes, $n_{\mathrm{o}}$ denotes the output layer nodes, $m$ is the constant, and $m \in[1,10]$.

4.3.3. Inversion Result. The suitable weights between the input layer and the hidden layer and the hidden layer and the output layer were attained through training BP neural network, and the temperatures of $T_{0}, T_{1}$, and $T_{10}$ and $T_{25}, T_{13}$, and $T_{22}$ measured by the adiabatic test were taken as the input values; then the thermal conductivity coefficient, specific heat, the released heat, and the hydration degree 


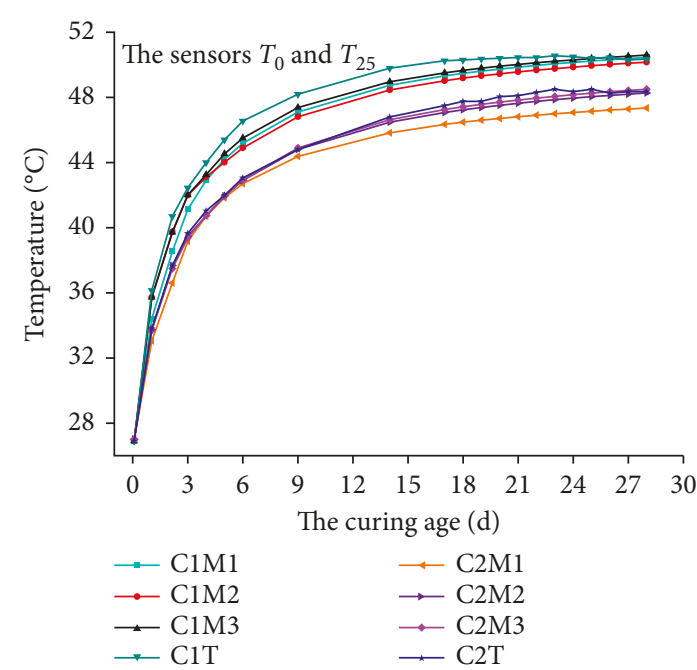

(a)

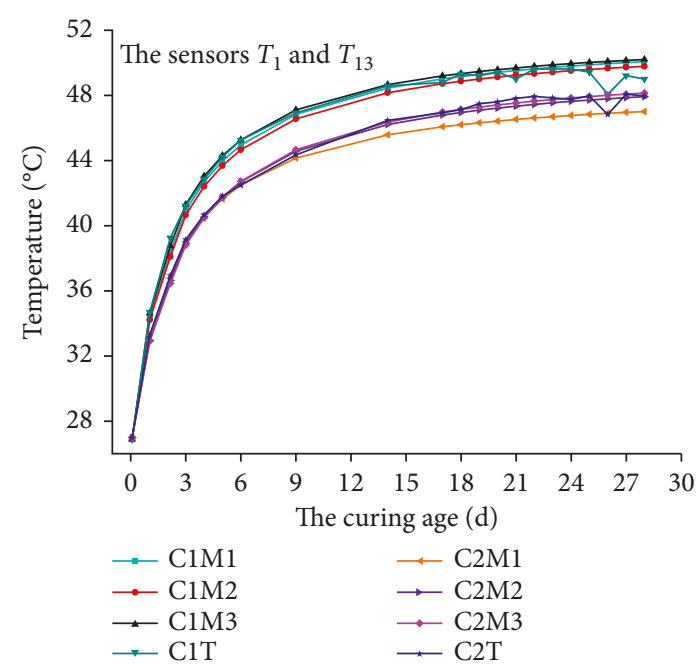

(c)

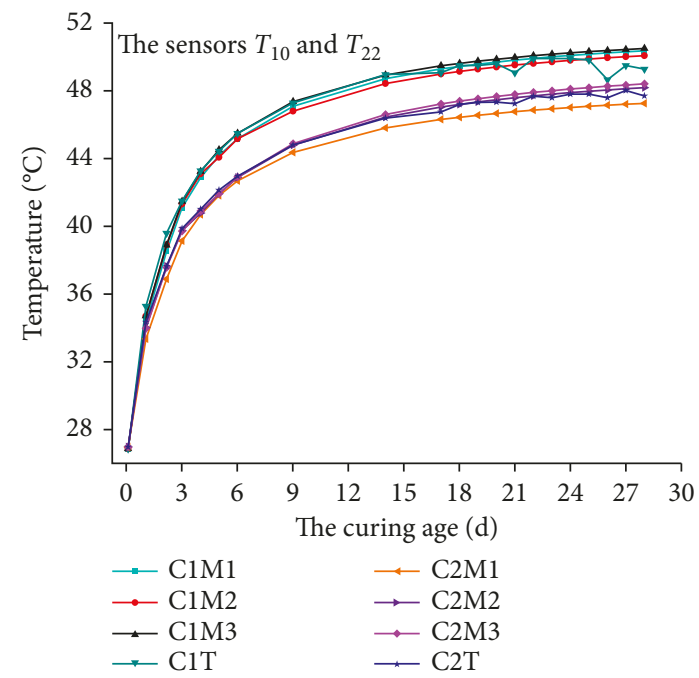

(e)

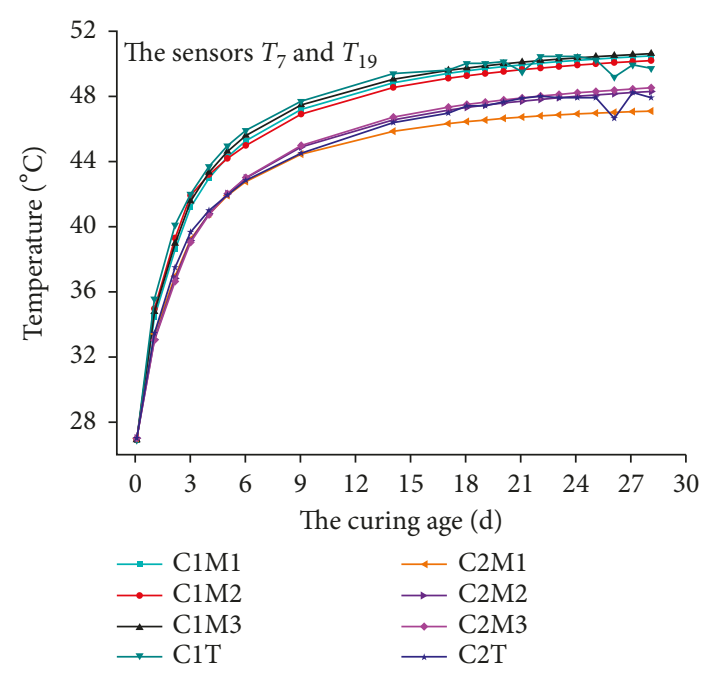

(b)

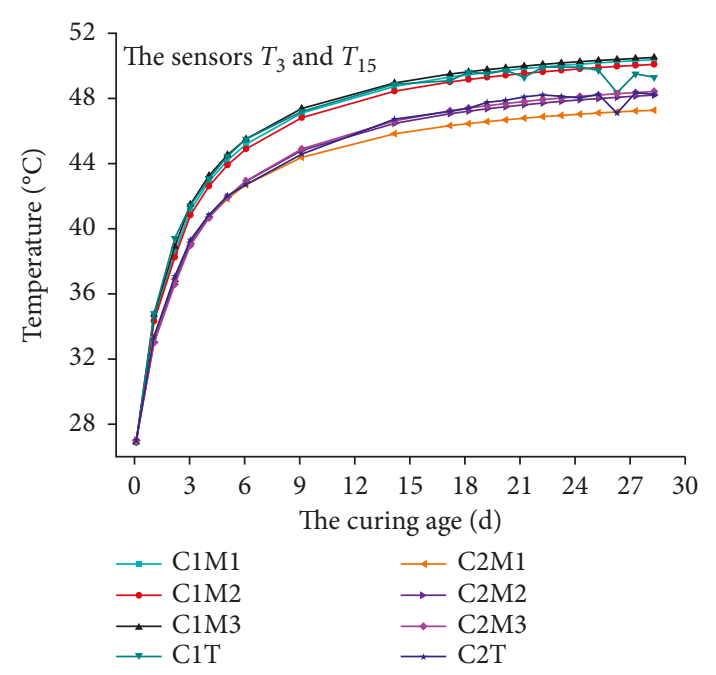

(d)

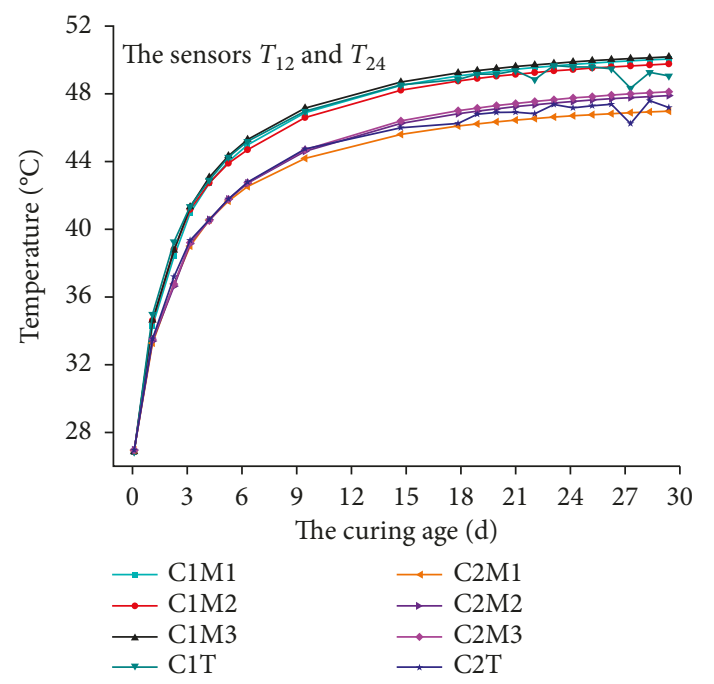

(f)

Figure 7: Historic curve of temperature at specified points. 
were predicted. At last, the thermal parameters required were obtained after all the data were processed through antinormalization, listed in Table 7.

\section{Numerical Analysis and Discussion}

5.1. Finite Element Analysis. The specimen used in Section 2 was simulated by finite element method, and the numerical model was meshed with 24000 hexahedral solid elements and 26061 nodes. The initial pouring temperature was $26.9^{\circ} \mathrm{C}$, and the ambient temperature was $25^{\circ} \mathrm{C}$. Moreover, the time step in the computation should be small enough in order to capture the released heat of the very early age in the sample. Previous studies suggest that the increase of time step within 0.2 day to 1 day is fine enough to achieve the required accuracy [23]. Therefore, the time step of 1 day was selected over the whole 28 days in the temperature field analysis.

All the surfaces of the sample should be insulated from the air, and there is no heat exchange between the specimen and the outside environment in the adiabatic temperature rise test. However, the simulation results showed that the temperature field of concrete was not completely uniform. It has also been proposed in the literature [12] that the adiabatic temperature rise chamber cannot sensitively and accurately track and adjust the temperatures during the entire experiment process, and the temperatures throughout the specimen are inconsistent. Therefore, the surface heat transfer coefficient $\beta$ was chosen to simulate the uneven temperature field of concrete in this study. Considering the insulation material used and the hysteresis of tracking temperature of the adiabatic test chamber, the coefficient $\beta$ was calculated by the formula mentioned in the literature [2], and the value of $\beta$ was taken as $24.1 \mathrm{~kJ} /\left(\mathrm{m}^{2} \cdot \mathrm{d} \cdot{ }^{\circ} \mathrm{C}\right)$.

Figure 6 shows the temperature distribution on the 28th day in a $3 \mathrm{D}$ cutoff view. From it, we can see that the temperatures are different within the specimen, and the temperatures near the center are higher than the ones near the concrete surface. Also the maximum temperature difference between the core and the edge is approximately $6.8^{\circ} \mathrm{C}$. Furthermore, the calculation results are consistent with the measured ones.

5.2. Result Analysis. In order to express the temperature variation of the specimen along the radial and the height sections, the temperatures of six positions corresponding to the sensors in the adiabatic temperature rise test were selected. Figure 7 indicates the comparison between the measured temperatures and the numerical calculation results of the specimens with the change of the curing ages at different positions.

(1) In different positions of the concrete, the temperature changing rules found in Method 1, Method 2, and Method 3 mentioned in Section 4 are consistent with the changing rules of the measured temperatures. The increase of temperature gradually slows down after a sharp growth in the initial period. Since a large amount of heat is generated by the initial cement hydration, the temperature increases rapidly in a short time. As the

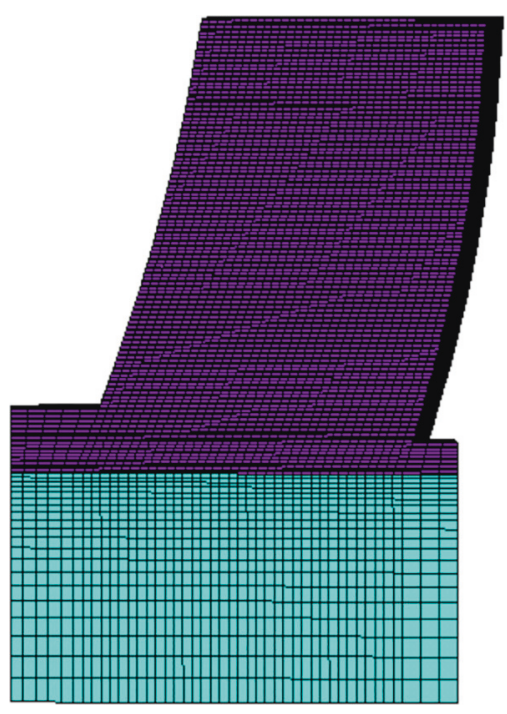

Figure 8: The finite element model of the block 22\#.

hydration reaction continues, the content of anhydrate cement decreases and the amount of hydration products increases, both of which will hinder the contact between the cement and water, and the increasing rate of temperature slows down.

(2) The numerical simulation results of the specimens C1 and $\mathrm{C} 2$ are compared, and it can be seen that Method 1 is fitting the specimen $\mathrm{C} 1$ well while the fitting deviation for the specimen $\mathrm{C} 2$ is larger. The curvature characteristic of the hyperbolic curve itself shows that the rate changes rapidly in the early stage and becomes gentler later. Obviously, the fitting form coincides with the hydration process of the specimen $\mathrm{C} 1$ better, but it is not applicable to the specimen $\mathrm{C} 2$ which has a significant temperature rise at the later stage.

(3) Through the analysis of calculation results obtained from the above three methods, a significant difference among the temperatures of six measuring points can be found; in the initial 7-day stage, the temperature historic curve obtained by Method 2 is the highest while that of Method 1 is the least. Afterward, the temperature historic curves obtained by those three methods are similar, and the temperatures calculated by Method 3 are always closest to the measured values during the whole curing ages. It can be explained that when the hydration degree is considered, the thermal conductivity coefficient is larger, specific heat is lower in the early age, and the temperatures of the same period rise rapidly. With the increase of the curing age, the thermal conductivity coefficient decreases and specific heat increases at the same time; thus, the temperature rise rate slows down. BP neural network in Method 3 is used to invert the thermal parameters which based on the hydration degree and modifies the thermal conductivity coefficient and specific heat of the whole process. Therefore, the simulation temperatures are in good agreement with the measured ones. 
TABLE 8: The related parameters of the dam.

\begin{tabular}{lcccc}
\hline $\begin{array}{l}\text { Density } \\
\left(\mathrm{kg} / \mathrm{m}^{3}\right)\end{array}$ & $\begin{array}{c}\text { Thermal conductivity } \\
\left(\mathrm{kJ} /\left(\mathrm{m} \cdot \mathrm{d} \cdot{ }^{\circ} \mathrm{C}\right)\right)\end{array}$ & $\begin{array}{c}\text { Specific heat } \\
\left(\mathrm{kJ} /\left(\mathrm{kg} \cdot{ }^{\circ} \mathrm{C}\right)\right)\end{array}$ & $\begin{array}{c}\text { Ultimate adiabatic temperature rise } \\
\left({ }^{\circ} \mathrm{C}\right)\end{array}$ & $\begin{array}{c}\text { The corresponding } \\
\text { value }\end{array}$ \\
\hline 2500 & 192.384 & 1.072 & 25 & 4 \\
\hline
\end{tabular}

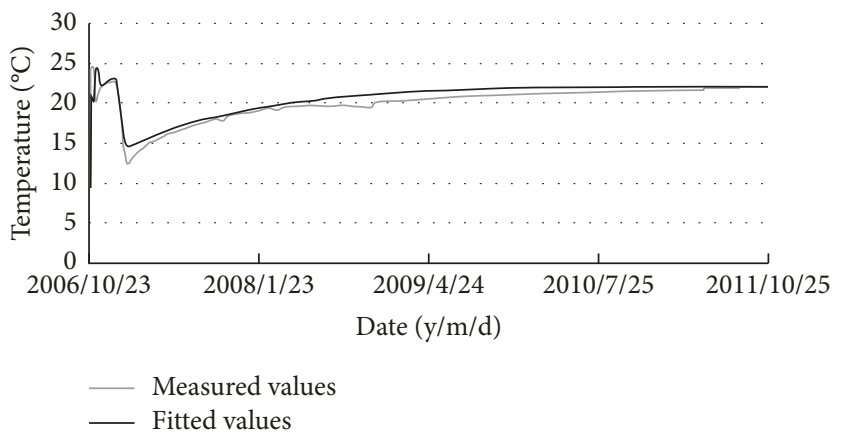

FIGURE 9: Historic curve of temperatures of block 22\#.

(4) From comprehensively studying the numerical simulation results of the different methods, the results of Method 2 are close to the measured values only in the early age, whereas the deviation between the simulation results and the measured ones at the later stage is slightly larger. Moreover, the temperatures calculated by Method 3 are similar to the measured values in the entire curing process. Therefore, it is necessary to consider the thermal parameters which change in accord with the hydration degree in the analysis of concrete temperature field in order to accurately reflect the temperature change of concrete hydration process and provide scientific basis for taking appropriate measures in design and construction of the practical projects.

(5) The results of the adiabatic temperature rise test show that the temperature near concrete core is the highest, and it decreases gradually along the radius, whereas the temperature near the bottom is slightly higher than that near the top. Consequently, the surface heat dissipation coefficient is necessary to be considered in the finite element numerical calculation.

5.3. Practical Application of the Proposed Method. Xiaowan dam is located in Yunnan Province. Block 22\# with temperature monitor is selected, and its finite element model is presented in Figure 8. And the related parameters are listed in Table 8.

Figure 9 shows the temperatures of fitted and measured ones. It is easy to notice that the temperature variation between them is within $3^{\circ} \mathrm{C}$. The good agreement between them further confirms the practice values of the proposed method.

\section{Conclusions}

The thermal model and the relevant parameters are the key issues in the study of temperature control and anticracking of the concrete structures. A further research about them has been accomplished through theoretical analysis, experiments, and numerical simulation, and the following conclusions can be drawn:

(1) The space-time evolution characteristics of fly ash concrete are revealed in this paper. The space distribution of temperatures is uneven, and the higher temperature near concrete core and lower temperature near concrete surface are found in the adiabatic temperature rise test. The temperature keeps increasing in the curing process, and the temperature rise rate in the first 3 days is faster while the rate at the later stage is slower.

(2) The thermal governing equation of the temperature rise of concrete as a function of the concrete age, heat generation of concrete, thermal conductivity, and specific heat which are dependent on the degree of hydration is presented, and the dynamic changes of concrete thermal properties during the hydration process are considered thoroughly.

(3) The BP neural network method is used to inverse the thermal parameters; the inversion results are substituted into the thermal model, and a practical BP algorithm which considers the degree of pozzolanic reaction of the fly ash is established.

(4) On the basis of the thermal parameters determined via the three methods mentioned in this paper, the finite element analyses of the temperature profile of fly ash concrete specimens are performed. Through comparing the temperature evolutions which are dependent on the thermal parameters calculated by three different methods, it can be found that the results calculated by the $\mathrm{BP}$ method are closer to the experimental results than others.

\section{Consent}

Informed consent was obtained from all individual participants included in the study.

\section{Conflicts of Interest}

The authors declare that they have no conflicts of interest.

\section{Acknowledgments}

This work has received financial support from special funds for basic scientific research business of Central University of China (no. 413000019). This support is gratefully acknowledged. The first author thanks the postgraduate students, Da $\mathrm{Li}$, and other staff for their assistance in laboratory experiment. 


\section{References}

[1] A. M. Nevile, Properties of Concrete, Longman, Harlow, UK, 1995.

[2] B. Zhu, Thermal Stresses and Temperature Control of Mass Concrete, China Electric Power Press, Beijing, China, 1999, in Chinese.

[3] H. N. Linsbaurer, A. R. Ingraffea, H. P. Rossmanith, and P. A. Wawrzynek, "Simulation of cracking in large arch dam: Part I II," Journal of Structural Engineering, vol. 115, no. 7, pp. 1599-1630, 1989.

[4] W. R. L. da Silva, V. Šmilauer, and P. Štemberk, "Upscaling semi-adiabatic measurements for simulating temperature evolution of mass concrete structures," Materials and Structures, vol. 48, no. 4, pp. 1031-1041, 2015.

[5] S. Choi, S. W. Cha, B. H. Oh, and I. H. Kim, "Thermo-hygromechanical behavior of early-age concrete deck in composite bridge under environmental loadings. Part 1: temperature and relative humidity," Materials and Structures, vol. 44, no. 7, pp. 1325-1346, 2011.

[6] S. Fu, T. He, G. Wang, S. Zhang, L. Zou, and S. Chen, "Evaluation of cracking potential for concrete arch dam based on simulation feedback analysis," Science China Technological Sciences, vol. 54, no. 3, pp. 565-572, 2011.

[7] J. Ding and S. Chen, "Simulation and feedback analysis of the temperature field in massive concrete structures containing cooling pipes," Applied Thermal Engineering, vol. 61, no. 2, pp. 554-562, 2013.

[8] E. M. R. Fairbairn, M. M. Silvoso, R. D. Toledo Filho, J. L. D. Alves, and N. F. F. Ebecken, "Optimization of mass concrete construction using genetic algorithms," Computers \& Structures, vol. 82, no. 2-3, pp. 281-299, 2004.

[9] G. De Schutter and L. Taerwe, "Specific heat and thermal diffusivity of hardening concrete," Magazine of Concrete Research, vol. 47, no. 172, pp. 203-208, 1995.

[10] K. H. Kim, S. E. Jeon, J. K. Kim, and S. Yang, "An experimental study on thermal conductivity of concrete," Cement and Concrete Research, vol. 33, no. 3, pp. 363-371, 2003.

[11] W. Cui, J. Wu, and H. Song, "Thermal field analysis of earlyage concrete considering effects of degree of hydration on thermal conductivity," Journal of Southeast University, vol. 45, no. 4, pp. 792-798, 2015, in Chinese.

[12] I. Y. T. Ng, P. L. Ng, and A. K. H. Kwan, "Effects of cement and water contents on adiabatic temperature rise of concrete," ACI Materials Journal, vol. 106, no. 1, pp. 42-49, 2009.

[13] G. De Schutter, "Finite element simulation of thermal cracking in massive hardening concrete elements using degree of hydration based material laws," Computers \& Structures, vol. 80, no. 27-30, pp. 2035-2042, 2002.

[14] A. G. A. Saul, "Principles underlying the steam curing of concrete at atmospheric pressure," Magazine of Concrete Research, vol. 2, no. 6, pp. 127-140, 1951.

[15] Z. P. Bazant, "Constructive equation for concrete creep and shrinkage based on thermodynamics of multiphase system," Materials and Structures, vol. 3, no. 1, pp. 3-36, 1970.

[16] H. Uysal, R. Demirboga, R. Sahin, and R. Gül, "The effects of different cement dosages, slumps, and pumice aggregate ratios on the thermal conductivity and density of concrete," Cement and Concrete Research, vol. 34, no. 5, pp. 845-848, 2004.

[17] W. Zhang, H. Min, X. Gu, Y. Xi, and Y. Xing, "Mesoscale model for thermal conductivity of concrete," Construction and Building Materials, vol. 98, no. 11, pp. 8-16, 2015.
[18] A. K. Schindler, Concrete Hydration, Temperature Development, and Setting at Early-Ages, Ph.D. dissertation, University of Texas at Austin, Austin, TX, USA, 2002.

[19] K. Y. Shin, S. B. Kim, J. H. Kim, M. Chung, and P. S. Jung, "Thermo-physical properties and transient heat transfer of concrete at elevated temperatures," Nuclear Engineering and Design, vol. 212, no. 1-3, pp. 233-241, 2002.

[20] K. Van Breugel, Simulation of Hydration and Formation of Structure in Hardening Cement-Based Materials, Ph.D. dissertation, Delft University Press, Delft, Netherlands, 1991.

[21] S. Akkurta, S. Ozdemir, G. Tayfur, and B. Akyol, "The use of GA-ANNs in the modeling of compressive strength of cement mortar," Cement and Concrete Research, vol. 33, no. 7, pp. 973-979, 2003.

[22] S. Fu and S. Chen, "Feedback analysis of the intake slope of Longtan hydropower project," International Journal of Rock Mechanics and Mining Sciences, vol. 41, no. 1, pp. 798-803, 2004.

[23] J. Conceição, R. Faria, M. Azenha, F. Mamede, and F. Souza, "Early-age behavior of the concrete surrounding a turbine spiral case: monitoring and thermo-mechanical modeling," Engineering Structures, vol. 81, pp. 327-340, 2014. 


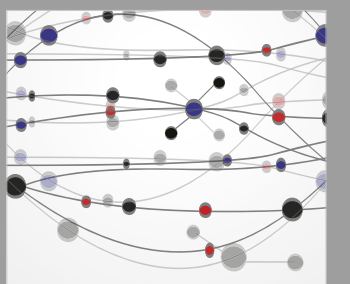

The Scientific World Journal
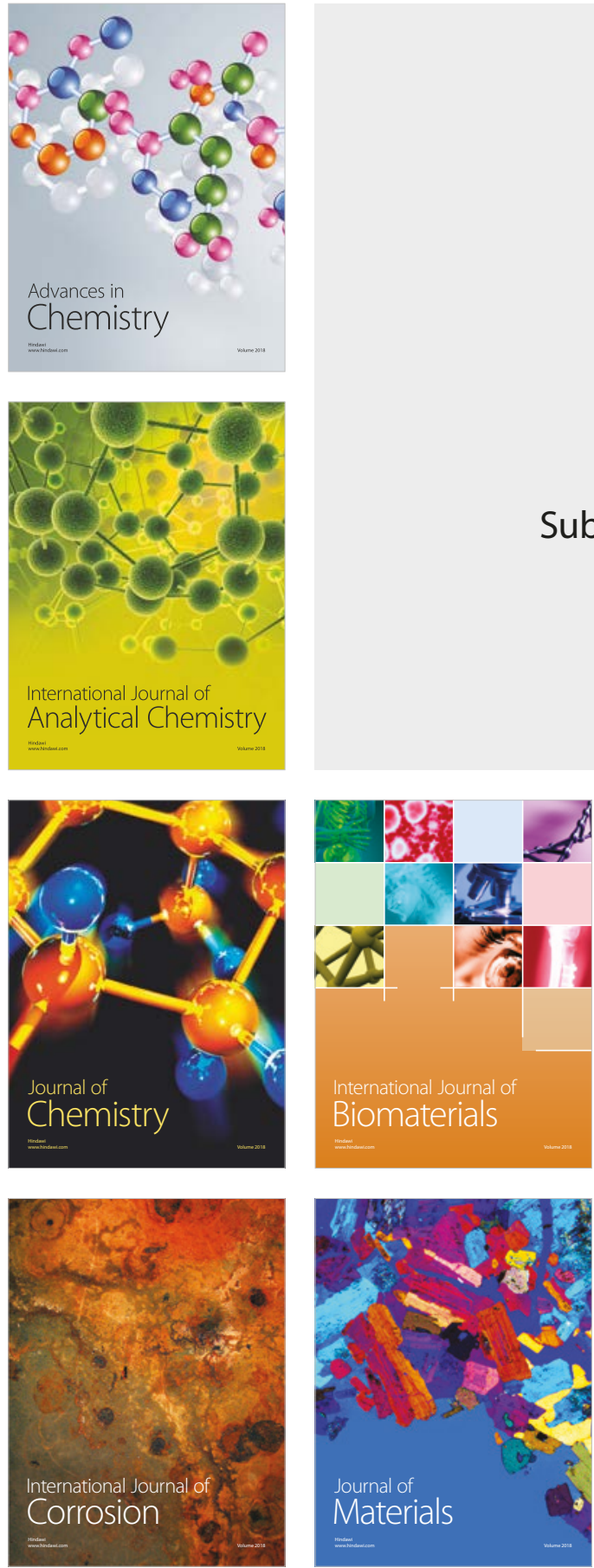

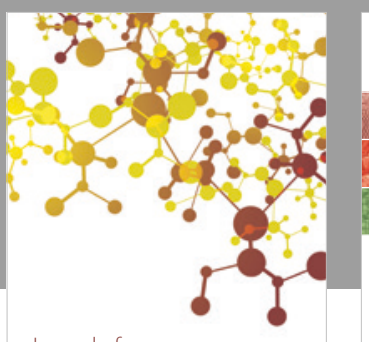

Journal of

Applied Chemistry
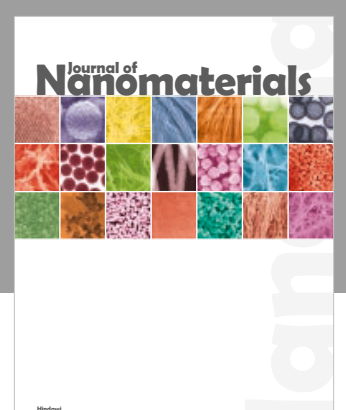

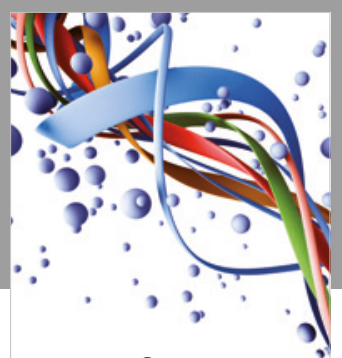

Scientifica

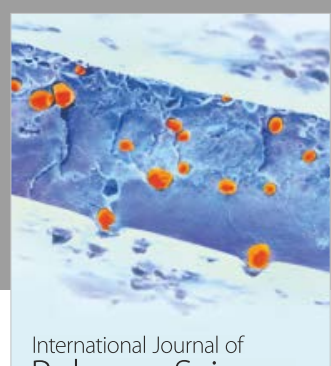

Polymer Science

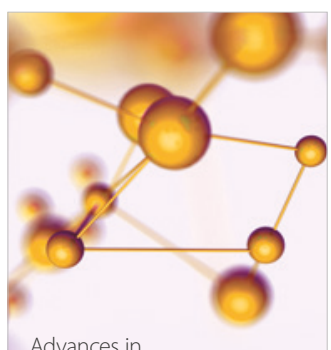

Physical Chemistry
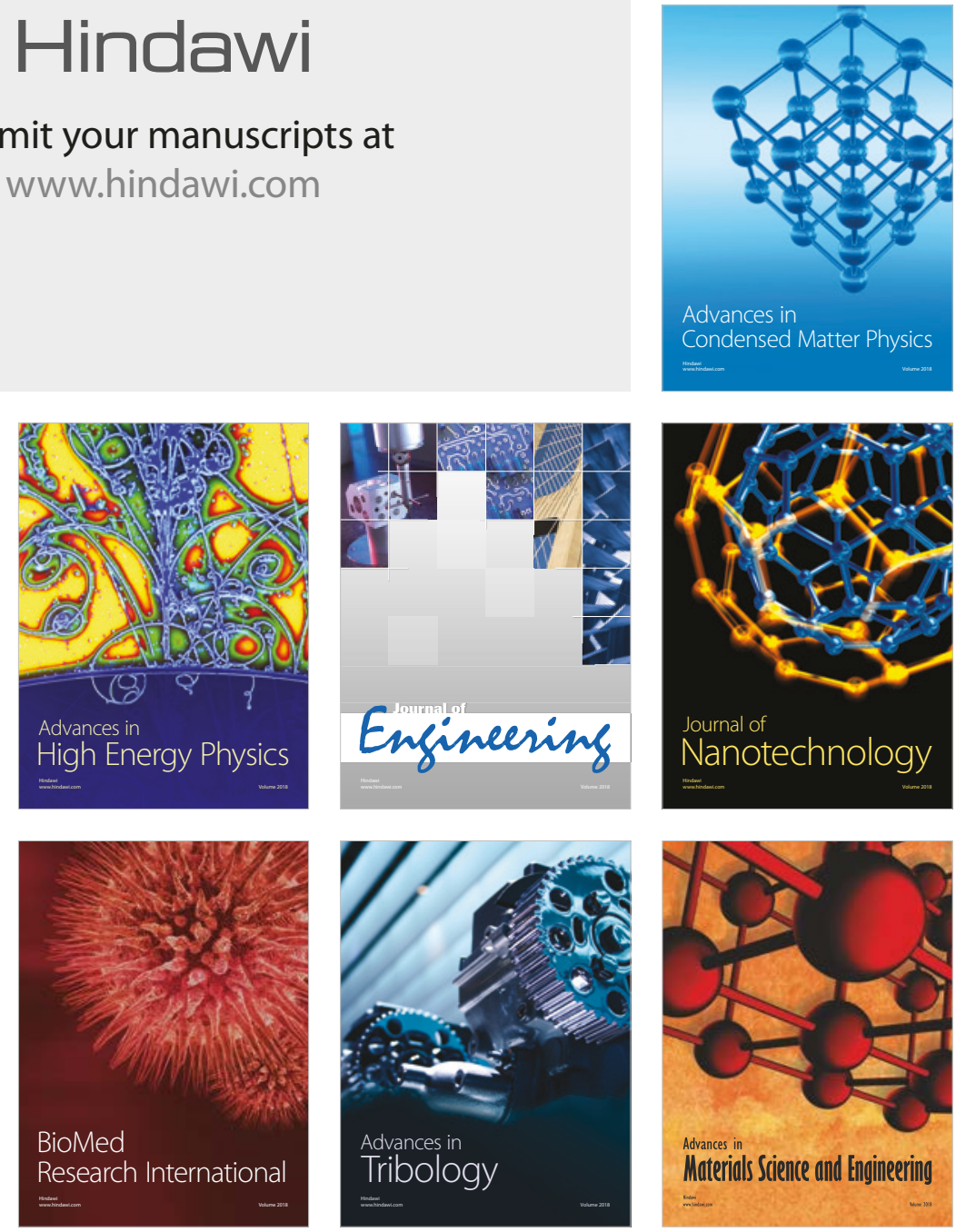